\title{
Antibiotic Prescription Pattern in Surgical Wards of MGM Hospital,
} Kamothe

\author{
Rohit Mahesh Sane, ${ }^{1, *}$ Savita Ramesh Shahani, ${ }^{1}$ and Ashok Allappa Kalyanshetti ${ }^{2}$ \\ ${ }^{1}$ Department of Pharmacology, MGM Medical College, Navi-Mumbai, India \\ ${ }^{2}$ Department of Surgery, MGM Medical College, Navi-Mumbai, India \\ "Corresponding author: Rohit Mahesh Sane, Department of Pharmacology, MGM Medical College, Navi-Mumbai, MH, India. Tel: +91-2224220909, E-mail: \\ rohitsane7@hotmail.com
}

Received 2017 July 10; Revised 2017 September 17; Accepted 2017 October 24.

\begin{abstract}
Background: Surgical antimicrobial prophylaxis refers to a brief course of antibiotic given just before surgery. Surgical site infection increases the hospital stay and prophylaxis has the potential to shorten hospital stay and fasten return to normal activity after discharge from the hospital. Therefore, the present study was undertaken to observe and analyse antimicrobial prescription pattern in patients that had undergone surgery at a tertiary care hospital.

Methods: This was a prospective case series study, with 200 patients irrespective of age or gender, presented to the surgical wards of a tertiary hospital and undergoing surgical intervention, conducted from October 2016 to April 2017. Permission of the institutional ethics committee was obtained before commencement of the study. Data was collected from all patients with the help of predesigned, pretested, and structured questionnaires. By comparison with international guidelines and national guidelines, the antibiotic prescription patterns were assessed. The researchers also observed whether a fixed protocol was followed for antimicrobial use for surgical prophylaxis.

Results: Overall, 200 patients were studied, with a mean age of 40.2 and a range of 23 to 70 years old with $64 \%$ being males and $36 \%$ being females. The surgeries of these patients were hernioplast 36\%, PCNL $8 \%$, haemorrhoidectomy $20 \%$, appendicectomy $4 \%$, hydrocoel surgery $16 \%$, lipoma excision $12 \%$, and cholecystectomy $4 \%$. The percentages of antibiotics used for these surgeries were cefotaxime $44 \%$, amikacin $88 \%$, ceftriaxone $52 \%$, metronidazole $30 \%$, and cefixime $54 \%$. These were then compared with the International and National guidelines for surgical prophylaxis.

Conclusions: Third generation cephalosporins were the preferred antibiotics for pre-operative use as well as for use in combination with aminoglycoside and metronidazole for better postoperative antibiotic coverage. This seems to be due to multiple factors in Indian settings, which makes Indian practitioners administer antibiotics for a prolonged duration.
\end{abstract}

Keywords: Surgical Antibiotic Prophylaxis, Prescription Pattern, Comparisons with International and National Guidelines

\section{Background}

Antibiotics are substances, which are obtained from one microorganism and prove fatal for other microorganism at low concentration. Antibiotics can either destroy 2 organisms (bactericidal) or prevent multiplication (bacteriostatic).

Antibiotics have 2 indications in surgery:

- To treat established infections.

- To prevent postoperative infections.

Surgical antimicrobial prophylaxis refers to a brief course of antibiotics given just before surgery. Surgical site infection (SSI) increases hospital stay and prophylaxis has the potential to shorten hospital stay and fasten return to normal activity after discharge from the hospital (1). There is inadequate scientific evidence to determine which groups of antimicrobials are most effective for antimicrobial prophylaxis.

The goals of prophylactic antimicrobial administration of antimicrobial agents to surgical patients are:

- To reduce incidence of surgical site infection.

- Use antibiotics in a manner that is supported by incidence of effectiveness.

- Minimize the effect of antibiotic on the patient's normal bacterial flora.

- Minimize adverse effects.

- Cause minimal change to the patient's host defences.

Surgeries can be categorized to four classes with increasing infection of bacterial contamination and subsequent incidence of postoperative infections (2):

-Clean wound; these are not inflamed or contaminated and do not involve surgeries on an internal organ. 
- Clean-contaminated wounds; these have no evidence of infection at the time of surgery but do involve surgeries on an internal organ.

- Contaminated wounds; these involve operating on an internal with spilling of contents from the organ into the wound.

- Dirty wound; these are wounds in which a known infection is present at the time of surgery.

Although a wide range of organisms can cause infections in surgical patients, antimicrobial agents that are prescribed should protect all expected infections considering the local resistance pattern and cost of drugs; thus, narrow spectrum and less expensive antimicrobial agents should be the first choice for prophylaxis during surgery (3).

Therefore, the present study was undertaken to observe and analyse antimicrobial prescription pattern in patients undergoing surgery in tertiary care hospitals and compare them with International (4) and National guidelines (5), which may provide benefit to a large portion of the population.

\section{Methods}

This prospective case series study was conducted from October 2016 to April 2017, at a tertiary care hospital in Navi-Mumbai. Two hundred cases presented to the surgical wards of this tertiary level hospital and undergoing surgical intervention were included. Permission of the institutional ethics committee was taken before commencement of the study. An informed written consent was taken from each patient before being included in the study. Those, who did not undergo a surgical intervention and those, who did not give consent for participation were excluded from the study.

This study compared the antibiotics prescribed in the surgical wards with the international guidelines (developed jointly by the American society of health-system pharmacists [ASHP], the infectious diseases society of America [IDSA], the surgical infection society [SIS], and the society for healthcare epidemiology of America [SHEA]) (4) and national guidelines (developed by national centre for disease control) (5) and observed whether a fixed protocol was followed for antimicrobial use for surgical prophylaxis.

The antibiotics prescribed for every individual patient were noted in detail (route, dose and duration) in the case record form followed up by analysis of the prescription pattern. It was also attempted to analyse the percentage of drugs prescribed by generic names. Data was entered in the MS-Excel software. Numerical data was summarized using means. Categorical data was summarized using percentages.

\section{Results}

A total of 200 patients in the Surgery wards were studied, with a gender ratio of males $64 \%$ : females $36 \%$. Average age was 40.2 years old with a range of 23 to 70 years.

Types of surgeries performed are shown in Figure 1.

All surgeries were further categorized as per absence or presence of infection before surgery (Haley RW (2)).

Figure 2 shows the various antibiotics prescribed in the surgical wards.

All prescribed antibiotics were listed in the national essential drug list except amikacin.

Ceftriaxone (21\%) was prescribed by its generic name, all remaining drugs (79\%) were prescribed by brand names.

Table 1 to Table 3 shows details of antibiotics prescribed for various categories of surgeries.

Fixed protocols for various categories of surgeries were not observed.

\section{Discussion}

The current study indicated that all patients received 3rd generation cephalosporins either alone or in combination with aminoglycoside. Metronidazole was prescribed for contaminated surgeries of gut and gall bladder, in which anaerobic organisms are expected to be present. It was tried to analyse the antibiotic prescription pattern and compare it with the patterns provided by International guidelines (4) and national treatment guidelines (5).

It was observed that in clean surgeries i.e., in hernioplasty, two trends of antibiotic prophylaxis were followed. In the first trend, cefotaxime ( 1 gm IV) was given $1 / 2$ hour. prior to surgery, which was followed by cefotaxime (1 gm IV BD) and amikacin (500 mg IV BD) post surgery for 5 days. The other trend was that ceftriaxone ( $1 \mathrm{gm} \mathrm{IV)}$ was given $1 / 2$ hour. Prior to surgery, followed by ceftriaxone (1 gm IV BD) and amikacin (500 $\mathrm{mg}$ IV BD) post surgery for 3 days; then followed up by cefixime (500 mg Oral BD) for 5 days making a total of 8 days. In hydrocoel surgeries, cefotaxime (1 gm IV) was given just before surgery followed by cefotaxime (1 gm IV BD) and amikacin (500 mg IV BD) for 3 days. Followed by cefixime ( $500 \mathrm{mg}$ Oral BD) for 5 days making a total duration of 8 days. In lipoma excision, ceftriaxone (1 gm IV) was given just before surgery followed by post-operative cefixime (500 $\mathrm{mg}$ Oral BD) for 5 days. In the international guidelines (4) and the national treatment guidelines (5), using a single dose of 1st generation cephalosporin (cefazolin) IV, just prior to surgery (within 


\section{Types of Surgeries}

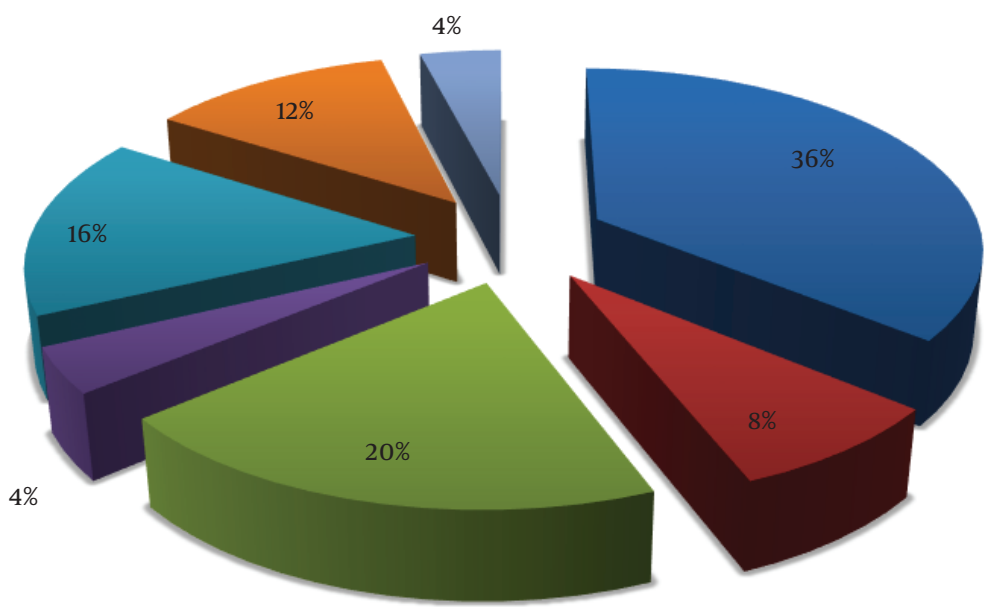

Hernioplasty

PCNL

Haemorrhoidectomy

Appendicectomy

Hydrocoel Surgery

Lipoma Excision

Cholecystectomy

Figure 1. Types of Surgeries Performed

Drugs Prescribed

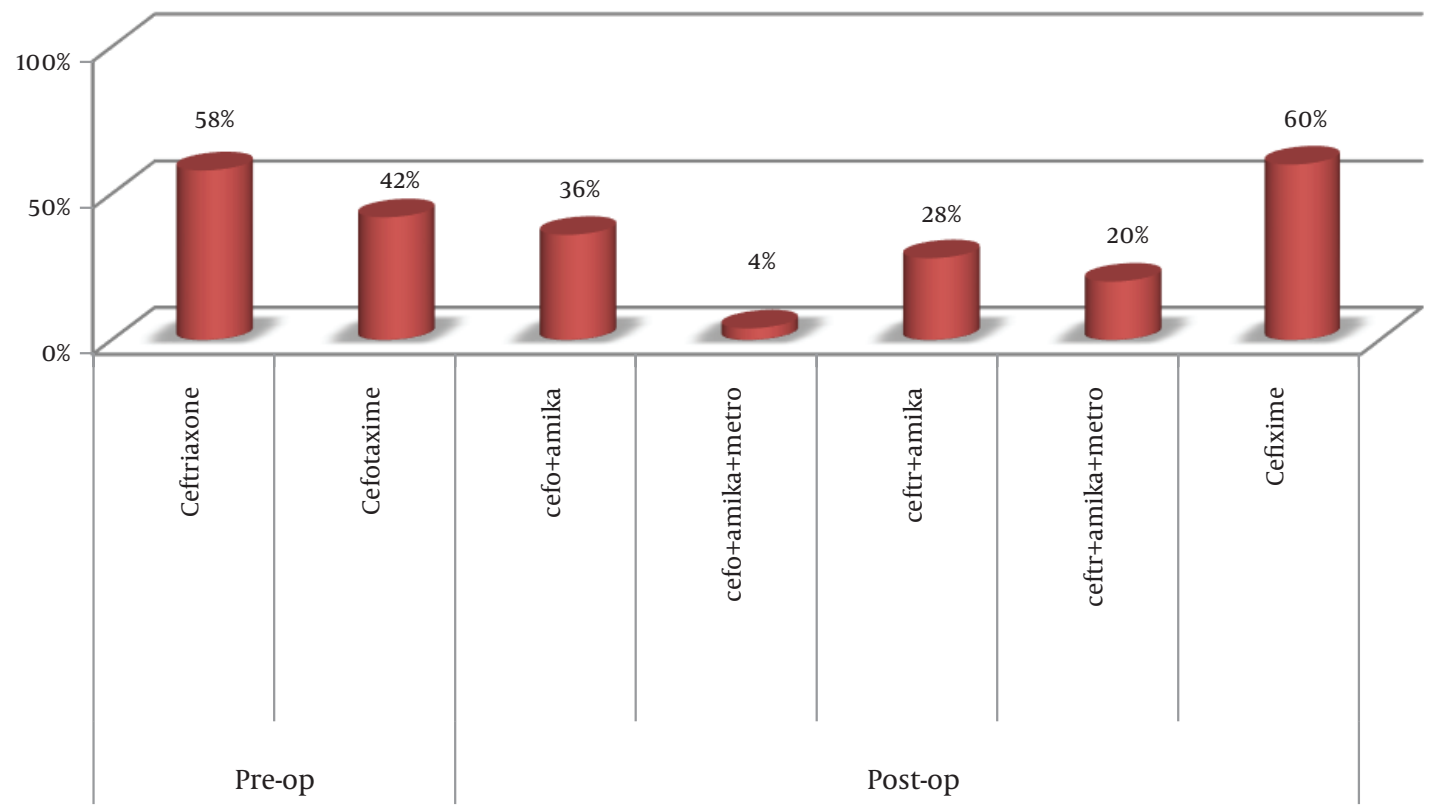

Figure 2. The Drugs Prescribed

60 minutes before starting surgery) and no post-operative antibiotics are recommended. The most common types of organisms affecting this category of surgery are aerobic gram-positive organisms (aerobic streptococci, Staphylo- 
Table 1. Clean Category of Surgery (128/200)

\begin{tabular}{|c|c|c|c|c|c|c|c|}
\hline & \multicolumn{3}{|c|}{ Pre-op } & \multicolumn{3}{|c|}{ Post-op } & \multirow[t]{2}{*}{ Total Duration } \\
\hline & Drug & Duration & Dose and Route & Drug & Duration & Dose and Route & \\
\hline \multirow{5}{*}{$\begin{array}{l}\text { Hernioplasty, } 72 \\
\text { surgeries }\end{array}$} & \multirow{2}{*}{ Cefotaxime } & \multirow{2}{*}{$\begin{array}{l}\text { Single dose } 1 / 2 \text { hour } \\
\text { before surgery }\end{array}$} & \multirow{2}{*}{$1 \mathrm{gm} \mathrm{IV}$} & Cefotaxime & 5 days & $1 \mathrm{~g}$ IV BD & \multirow{2}{*}{5 days } \\
\hline & & & & Amikacin & 5 days & $500 \mathrm{mg}$ IV BD & \\
\hline & \multirow{3}{*}{ Ceftriaxone } & \multirow{3}{*}{$\begin{array}{l}\text { Single dose } 1 / 2 \text { hour } \\
\text { before surgery }\end{array}$} & \multirow{3}{*}{$1 \mathrm{gm} \mathrm{IV}$} & Ceftriaxone & 3 days & $1 \mathrm{~g} \mathrm{IV} \mathrm{BD}$ & \multirow{3}{*}{8 days } \\
\hline & & & & Amikacin & 3 days & $500 \mathrm{mg}$ IV BD & \\
\hline & & & & Cefixime & 5 days & $500 \mathrm{mg}$ Oral BD & \\
\hline \multirow{3}{*}{$\begin{array}{l}\text { Hydrocoel } \\
\text { surgery, } 32 \\
\text { surgeries }\end{array}$} & \multirow{3}{*}{ Cefotaxime } & \multirow{3}{*}{$\begin{array}{l}\text { Single dose } 1 / 2 \text { hour } \\
\text { before surgery }\end{array}$} & \multirow{3}{*}{$1 \mathrm{gm} \mathrm{IV}$} & Cefotaxime & 3 days & $1 \mathrm{~g} \mathrm{IV} \mathrm{BD}$ & \multirow{3}{*}{8 days } \\
\hline & & & & Amikacin & 3 days & 500 mg IV BD & \\
\hline & & & & Cefixime & 5 days & 500 mg Oral BD & \\
\hline $\begin{array}{l}\text { Lipoma excision, } \\
24 \text { surgeries }\end{array}$ & Ceftriaxone & $\begin{array}{l}\text { Single dose } 1 / 2 \text { hour } \\
\text { before surgery }\end{array}$ & $1 \mathrm{gm} \mathrm{IV}$ & Cefixime & 5 days & $500 \mathrm{mg}$ Oral BD & 5 days \\
\hline
\end{tabular}

Table 2. Clean-contaminated Category of Surgery (24/200)

\begin{tabular}{|c|c|c|c|c|c|c|c|}
\hline & \multicolumn{3}{|c|}{ Pre-op } & \multicolumn{3}{|c|}{ Post-op } & \multirow[t]{2}{*}{ Total Duration } \\
\hline & Drug & Duration & Dose and Route & Drug & Duration & Dose and Route & \\
\hline \multirow{3}{*}{ PCNL, 16 surgeries } & \multirow{3}{*}{ Ceftriaxone } & \multirow{3}{*}{$\begin{array}{l}\text { Single dose } 1 / 2 \text { hour } \\
\text { before surgery }\end{array}$} & \multirow{3}{*}{$1 \mathrm{gm} \mathrm{IV}$} & Ceftriaxone & 3 days & $1 \mathrm{~g}$ IV BD & \multirow{3}{*}{8 days } \\
\hline & & & & Amikacin & 3 days & $500 \mathrm{mg}$ IV BD & \\
\hline & & & & Cefixime & 5 days & 500 mg Oral BD & \\
\hline \multirow{3}{*}{$\begin{array}{l}\text { Appendicectomy, } \\
8 \text { surgeries }\end{array}$} & \multirow{3}{*}{ Cefotaxime } & \multirow{3}{*}{$\begin{array}{l}\text { Single dose } 1 / 2 \text { hour } \\
\text { before surgery }\end{array}$} & \multirow{3}{*}{$1 \mathrm{gm} \mathrm{IV}$} & Cefotaxime & 3 days & $1 \mathrm{~g} \mathrm{IV} \mathrm{BD}$ & \multirow{3}{*}{8 days } \\
\hline & & & & Amikacin & 3 days & 500 mg IV BD & \\
\hline & & & & Cefixime & 5 days & $500 \mathrm{mg}$ Oral BD & \\
\hline
\end{tabular}

Table 3. Contaminated Category of Surgery (48/200)

\begin{tabular}{|c|c|c|c|c|c|c|c|}
\hline & \multicolumn{3}{|c|}{ Pre-op } & \multicolumn{3}{|c|}{ Post-op } & \multirow{2}{*}{$\begin{array}{c}\text { Total } \\
\text { Duration }\end{array}$} \\
\hline & Drug & Duration & $\begin{array}{c}\text { Dose and } \\
\text { Route }\end{array}$ & Drug & Duration & $\begin{array}{c}\text { Dose and } \\
\text { Route }\end{array}$ & \\
\hline \multirow{3}{*}{$\begin{array}{l}\text { Haemorrhoidectomy, } 40 \\
\text { surgeries }\end{array}$} & \multirow{3}{*}{ Ceftriaxone } & \multirow{3}{*}{$\begin{array}{c}\text { Single dose } 1 / 2 \\
\text { hour before } \\
\text { surgery }\end{array}$} & \multirow{3}{*}{$1 \mathrm{gm} \mathrm{IV}$} & Ceftriaxone & 5 days & 1g IV BD & \multirow{3}{*}{5 days } \\
\hline & & & & Amikacin & 5 days & 500 mg IV BD & \\
\hline & & & & Metronidazole & 5 days & $100 \mathrm{mg}$ IV TDS & \\
\hline \multirow{3}{*}{$\begin{array}{l}\text { Cholecystectomy, } 8 \\
\text { surgeries }\end{array}$} & \multirow{3}{*}{ Cefotaxime } & \multirow{3}{*}{$\begin{array}{l}\text { Single dose } 1 / 2 \\
\text { hour before } \\
\text { surgery }\end{array}$} & \multirow{3}{*}{$1 \mathrm{gm} \mathrm{IV}$} & Cefotaxime & 5 days & 1gm IV BD & \multirow{3}{*}{5 days } \\
\hline & & & & Amikacin & 5 days & 500 mg IV BD & \\
\hline & & & & Metronidazole & 5 days & $100 \mathrm{mg}$ IV TDS & \\
\hline
\end{tabular}

coccus species and Enterococcus species) (4), which respond well to 1st generation cephalosporins.

In clean-contaminated surgeries, it was observed that in appendicectomy, cefotaxime ( 1 gm IV) was given $1 / 2$ hour before surgery followed post operatively with cefotaxime (1 gm IV BD) and amikacin (500 mg IV BD) for 3 days; followed by cefixime (500 mg Oral BD) for 5 days making a total du- ration of 8 days. For PCNL, ceftriaxone ( $1 \mathrm{~g}$ IV) was given just before surgery followed post operatively by ceftriaxone (1gm IV BD) and amikacin (500 mg IV BD) for 3 days; followed by cefixime (500 mg Oral BD) for 5 days making a total duration of 8 days. In the International guidelines (4) and the National guideline (5), a single dose of cefazolin ( $1 \mathrm{~g} \mathrm{IV})$ with metronidazole (100 mg IV) or a 2nd generation 
cephalosporin cefoxitin (1g IV) is given just prior to surgery (within 60 minutes before starting surgery) and no postoperative antibiotics are administered. The most common organisms affecting this surgery are anaerobic and aerobic gram-negative organisms (B. fragilis and E. coli) (4), which respond well to 2 nd generation cephalosporins.

For contaminated surgeries, i.e. haemorrhoidectomy, ceftriaxone (1 gm IV) was given just before surgery. Postsurgery, ceftriaxone (1 g IV BD), amikacin (500 mg IV BD) and metronidazole (100 mg IV TDS) were administered for 5 days. In cholecystectomy, cefotaxime ( $1 \mathrm{~g}$ IV) was given just prior to surgery followed by cefotaxime (1 $\mathrm{gm}$ IV BD), amikacin (500 mg IV BD), and metronidazole (100 mg IV TDS) for 5 days. In the international guidelines (4) and the national guideline (5), a single dose of 1st generation cephalosporin (cefazolin) with metronidazole (100 mg IV) or a 2nd generation cephalosporin cefoxitin (1 m IV) was given just prior to surgery (within 60 minutes before starting surgery) and no post-operative antibiotics. If this surgery was performed at institutions where there was increasing resistance to 1 st and 2 nd generation cephalosporins, then a single dose of ceftriaxone plus metronidazole was recommended. The most common organisms affecting this type of surgery are anaerobes like B. fragilis and Clostridium species (4), which respond well to metronidazole and aerobes like E. coli, Klebsiella species and Enterococci (4), which respond well to 2nd generation cephalosporins.

In Indian studies conducted by Rehan (6) and Parulekar (7), at a tertiary care hospital, 3rd generation cephalosporins were prescribed to almost half of all the patients, who received preoperative antibiotics and for a prolonged duration of 5 to 10 days post surgery, which was inappropriate according to SIGN and ASHP guidelines. Similar studies conducted in other countries (8-16), revealed a high frequency of prescription of antibiotics when not required, inappropriate choice, and use of antibiotics for a prolonged duration. In the current study too, a similar prescription pattern was found, where 3rd generation cephalosporins were prescribed to all patients preoperatively. Overall, $58 \%$ of participants received ceftriaxone and $42 \%$ received cefotaxime prior to their surgery and postoperative antibiotics were continued for a prolonged duration of 5 to 8 days.

Prolonged antimicrobial treatment is due to the false belief of surgeons that it provides better coverage against SSIs in overcrowding situations, like that of this tertiary care hospital. Along with this, low nurse to patient ratio, lack of regular surveys of antimicrobial usage, reassessment of prescribing practices, regular pharmacovigilance and departmental and consensus meetings play important roles for prolonged antimicrobial usage.
A protocol to administer surgical prophylaxis should be generated for the hospital, taking into account the infection rates along with the common types of infecting organisms. Policies to formulate and promote the development, dissemination, and adoption of evidence-based antibiotics should be made. The policy should be simple, clear, and implementable. There should be constant monitoring with periodic audit to ensure adherence is warranted. This will ensure that clear protocol based guidelines are followed thus minimizing resistance and over use, as recommended by Agrawal (17) and Maria Aparecida (18) in their studies.

\subsection{Conclusion}

Third generation cephalosporins were the preferred antibiotics for pre-operative use as well as for the use in combination with aminoglycoside and metronidazole for better postoperative antibiotic coverage. Thus, this seems to be due to multiple factors in Indian settings, which makes Indian practitioners administer antibiotics for a prolonged duration. Thus, the study documents a need to reform the current antibiotic usage and development of hospital-based antibiotic guidelines for rational utilization.

\section{Footnotes}

Conflict of Interest: None declared.

Implications: To provide feedback to concerned departments, which may help in planning for policies of antibiotic prescription pattern.

\section{References}

1. Culver DH, Horan TC, Gaynes RP, Martone WJ, Jarvis WR, Emori TG, et al. Surgical wound infection rates by wound class, operative procedure, and patient risk index. National Nosocomial Infections Surveillance System. Am J Med.1991;91(3B):152S-7S. [PubMed: 1656747].

2. Haley RW. Nosocomial infections in surgical patients: Developing valid measures of intrinsic patient risk. American J Med.1991;91(3):14551. doi: 10.1016/0002-9343(91)90360-a.

3. Mangram AJ, Horan TC, Pearson ML, Silver LC, Jarvis WR. Guideline for Prevention of Surgical Site Infection, 1999. Centers for Disease Control and Prevention (CDC) Hospital Infection Control Practices Advisory Committee.Am Jinfect Control.1999;27(2):97-132. quiz133-4; discussion 96. [PubMed: 10196487].

4. ASHP therapeutic guidelines . Clinical practice guidelines for antimicrobial prophylaxis in surgery. Am J Health-Syst Pharm. 2013;70:624709.

5. National Centre For Disease Control. National treatment guidelines for antimicrobial use in infectious diseases. Directorate General of Health Services, Ministry of Health \& Family Welfare, Govt. of India; 2016. 41 $\mathrm{p}$

6. Rehan HS. Surgical antibiotic prophylaxis in a tertiary care teaching hospital in India. Inter J Infec Control. 2010;6(2):1-6. 
7. Parulekar L, Soman R, Singhal T, Rodrigues C, Dastur FD, Mehta A. How good is compliance with surgical antibiotic prophylaxis guidelines in a tertiary care private hospital in India? A prospective study. Indian J Surg. 2009;71(1):15-8. doi: 10.1007/s12262-009-0004-9. [PubMed: 23133102].

8. Choi WS, Song JY, Hwang JH, Kim NS, Cheong HJ. Appropriateness of antibiotic prophylaxis for major surgery in Korea. Infect Control Hosp Epidemiol. 2007;28(8):997-1002. doi: 10.1086/519180. [PubMed: 17620250].

9. Fennessy BG, O’Sullivan MJ, Fulton GJ, Kirwan WO, Redmond HP. Prospective study of use of perioperative antimicrobial therapy in general surgery. Surg Infect (LarChmt). 2006;7(4):355-60. doi: 10.1089/sur.2006.7.355. [PubMed: 16978078].

10. Askarian M, Moravveji AR, Mirkhani H, Namazi S, Weed H. Adherence to American Society of Health-System Pharmacists surgical antibiotic prophylaxis guidelines in Iran. Infect Control Hosp Epidemiol. 2006;27(8):876-8. doi: 10.1086/506405. [PubMed: 16874651].

11. Yalcin AN, Erbay RH, Serin S, Atalay H, Oner O, Yalcin AD. Perioperative antibiotic prophylaxis and cost in a Turkish University Hospital. Infez Med. 2007;15(2):99-104. [PubMed: 17598996].

12. Tourmousoglou CE, Yiannakopoulou E, Kalapothaki V, Bramis J, St Papadopoulos J. Adherence to guidelines for antibiotic prophylaxis in general surgery: a critical appraisal. J Antimicrob Chemother.
2008;61(1):214-8. doi: 10.1093/jac/dkm406. [PubMed: 17999981].

13. Bennett NJ, Bull AL, Dunt DR, Russo PL, Spelman DW, Richards MJ. Surgical antibiotic prophylaxis in smaller hospitals. ANZ Surg. 2006;76(8):676-8. doi:10.1111/j.1445-2197.2006.03826.x. [PubMed: 16916381].

14. Gu YA, Hong LC, Prasannan S. Appropriate antibiotic administration in elective surgical procedures: Still missing the message. Asian J Surg. 2005;28(2):104-8. doi: 10.1016/s1015-9584(09)60272-4.

15. Hu S, Liu X, Peng Y. Assessment of antibiotic prescription in hospitalised patients at a Chinese university hospital. J Infect. 2003;46(3):161-3. [PubMed: 12643864].

16. Erbay A, Bodur H, Akinci E, Colpan A. Evaluation of antibiotic use in intensive care units of a tertiary care hospital in Turkey. J Hosp Infect. 2005;59(1):53-61. doi:10.1016/j.jhin.2004.07.026. [PubMed: 15571854].

17. Agrawal M, Sharma PK, Dhaneria SP. Clinical practice audit of perioperative antimicrobial prophylaxis in a tertiary care hospital - Do routine academic activities improve adherence to practice guidelines?. Reviews Recent Clin Trial. 2016.

18. Maria AMP, Maria Patelli JL, Irene da Rocha HG, Gun BM. The implementation of a surgical antibiotic prophylaxis program: The pivotal contribution of the hospital pharmacy. Am J Infect Control. 2002;30(1):49-56. 